\title{
Antioxidant, Antimicrobial, and Free Radical Scavenging Potential of Aerial Parts of Periploca aphylla and Ricinus communis
}

\author{
Jamshed Iqbal, ${ }^{1}$ Sumera Zaib, ${ }^{1}$ Umar Farooq, ${ }^{2}$ Afsar Khan, ${ }^{2}$ Irum Bibi, ${ }^{2}$ and Saba Suleman ${ }^{2}$ \\ ${ }^{1}$ Department of Pharmaceutical Sciences, COMSATS Institute of Information Technology, Abbottabad 22060, Pakistan \\ ${ }^{2}$ Department of Chemistry, COMSATS Institute of Information Technology, Abbottabad 22060, Pakistan
}

Correspondence should be addressed to Jamshed Iqbal, drjamshed@ciit.net.pk

Received 6 April 2012; Accepted 18 May 2012

Academic Editors: T. Irie, R. Thurmond, and T. B. Vree

Copyright (C) 2012 Jamshed Iqbal et al. This is an open access article distributed under the Creative Commons Attribution License, which permits unrestricted use, distribution, and reproduction in any medium, provided the original work is properly cited.

\begin{abstract}
Context. Many diseases are associated with oxidative stress caused by free radicals. Objective. The present study evaluated the in vitro antioxidant and antibacterial activities of various extracts of aerial parts of Periploca aphylla and Ricinus communis. Materials and Methods. In vitro antioxidant activities of the plant extract were determined by DPPH and NO scavenging method. Superoxide anion radical activity was measured by the reduction of nitro blue tetrazolium as compared with standard antioxidants. Total phenolic contents and antibacterial activities of these plants were determined by gallic acid equivalent (GAE) and serial tube dilution method, respectively. Results. Plants showed significant radical scavenging activity. The results were expressed as IC $50 . n$ Propyl gallate and 3-t-butyl-4-hydroxyanisole were used as standards for antioxidant assay. All the extracts of both plants showed comparable $\mathrm{IC}_{50}$ to those of standards. Plants extract exhibited high phenolic contents and antibacterial activities were comparable with standard drug, Ciprofloxacin. Discussion and Conclusion. The present study provides evidence that Periploca aphylla and Ricinus communis prove to be potent natural antioxidants and could replace synthetic antioxidants. Plants can also be used against pathogenic bacterial strains.
\end{abstract}

\section{Introduction}

Epidemiological studies have brought into being that intake of antioxidants such as vitamin $\mathrm{C}$ reduces the risk of coronary heart diseases and cancer [1]. It is possible to reduce the risk of chronic diseases and to prevent disease progression by either enhancing the body's natural antioxidant defense or by supplementing with proven dietary antioxidants [2]. Several studies revealed that phenols, mainly flavonoids, from some medicinal plants are safe and bioactive, and have antioxidant properties and exert anticarcinogenic, antimutagenic, antitumor, antibacterial, antiviral, and anti-inflammatory effects [3]. Therefore, in current years, substantial attention has been directed towards credentials of plants with antioxidant ability that may be used for human expenditure.

Nitric oxide (NO), a powerful neurotransmitter, exerts influence on a number of functions including vasodilation, neurotransmission, synaptic plasticity, and memory in the central nervous system $[4,5]$. Besides mediating normal function, $\mathrm{NO}$ has been implicated in pathophysiologic states like neurodegenerative and Alzheimer's disease. Overproduction of NO can mediate toxic effects, for example, DNA fragmentation, cell damage, and neuronal cell death $[6,7]$.

Periploca aphylla belongs to the genus Periploca (Asclepiadaceae), which contains 12 species and out of these only three species have been found in Pakistan. Medicinally, genus Periploca is very important. The root bark of Periploca sepium contains the substances that are antitumor in nature and is used to relieve chronic congestive heart failure [8], whereas its essential oil has also shown insecticidal as well as antimicrobial and antioxidant activities. Periploca sepium contains a pregnane glycoside "Periplocoside E." It is a highly immunosuppressive compound, which stops the activation of T-cells in vitro and in vivo. This plant is used to cure the autoimmune disorders of T-cells and also has shown antitumor activity [9]. The roots of P. sepium and P. forrestii 
are useful for the treatment of rheumatoid arthritis and wounds. Periploca laevigata is taken as tea and is used as a herbal medicine for the treatment of diabetes and headache and also possesses antioxidant and free radical scavenging activities.

Locally, Periploca aphylla is known as "Bata" or "Barara." The milky juice of this plant is applied to tumors and swellings. It is useful for the treatment of swollen joints, cough, and flu. The plant is also used to treat skin diseases, ulcer, and constipation. Various constituents isolated from $P$. aphylla have shown inhibitory action of $\alpha$-glucosidase type VI and antibacterial activities [10].

Ricinus communis (commonly known as castor oil plant) belongs to family Euphorbiaceae. In Pakistan, the plant is distributed in Sub-Himalayan track and also in plain areas. Ricinus communis is well known for its biological activities; most important of which are hepatoprotective, laxative, antidiabetic, and antifertility activities. The seeds yield castor oil, which has been used to treat liver infections and to cure inflammation in Indian system of medicine. Free radical scavenging and anti-inflammatory activities of methanolic extract of $R$. communis roots have been studied in Wistar albino rats [11]. A 50\% ethanolic extract of Ricinus communis roots showed antidiabetic activity [12]. The castor oil is taken in diarrhea of childhood and sometimes in combination with opium, in inflammatory conditions of bowels, to the lying-in women after child birth, and also to facilitate delivery before child birth. Castor oil is also used for the treatment of constipation. In addition, castor oil cake's used as manure. The seeds are also used for treatment of warts, colic, enteritis, ringworms, dandruff, for itching, hemorrhoids, for hair loss and also as laxative before X-ray examination of bowels. In India, the leaf poultice is applied to boils and sores, used to treat fever and headache. Swellings and gout are cured by heated leaves. The plant is also useful for the treatment of several skin infections such as scrofula and dog bite. Pharmacological activities of $R$. communis are also remarkable such as antiviral [13], antioxidant [11], antifertility [14-18], antipsychotic, convulsant [19], hepatoprotective, insecticidal [20], haemagglutination, and anti-inflammatory [11]. Castor oil is proved to be one of the cheapest, easily available and highly useful purgatives of the Pharmacopoeia, for old people and children in all delicate conditions.

Plants extracts were tested for various activities such as antioxidant, antibacterial, nitric oxide, and superoxide scavenging, and their total phenolic contents have been determined.

\section{Methods}

2.1. Plant Material Collection. The plant Periploca aphylla was collected from Mansehra, Pakistan, in May, 2009. The plant Ricinus communis was collected from Haripur, Pakistan, in May, 2010. The plants were identified by Dr. Manzoor Ahmad (taxonomist) at the Department of Botany, Post-Graduate College, Abbottabad, KPK, Pakistan. A voucher specimen (no. 3571) of Periploca aphylla and (no. 3570) of Ricinus communis have been deposited at the herbarium of the above department.

2.2. Fractionation and Extract Preparation. The shade-dried powdered form of aerial parts of Periploca aphylla $(25 \mathrm{~kg})$ was extracted three times with methanol at room temperature. The brownish crude extract (1606g) was then suspended in water and was partitioned successively between $n$-hexane (260 g), chloroform (425 g), ethyl acetate (247 g), and $n$ butanol $(313 \mathrm{~g})$. Crude extract as well as all the other fractions were subjected to biological activities.

The air-dried and ground aerial parts of Ricinus communis $(7 \mathrm{~kg}$ ) was soaked in methanol at room temperature and then filtered. The methanolic extract was evaporated and a thick greenish matrix (325 g) was obtained, which was partitioned into four fractions: $n$-hexane $(87 \mathrm{~g})$, chloroform ( $59 \mathrm{~g})$, ethyl acetate $(55 \mathrm{~g})$, and $n$-butanol (96 g). All the four fractions were evaluated for biological activities.

2.3. Antioxidant Assay. The free radical scavenging capacity of the compounds was measured by 1,1-diphenyl-2picrylhydrazyl (DPPH) method [21] with little modifications. Test compounds were allowed to react with stable free radical, DPPH for half an hour at $37^{\circ} \mathrm{C}$. The concentration of DPPH was $100 \mathrm{mM}$. The plants extracts were dissolved in DMSO, while the DPPH solution was prepared in methanol. $n$-Propyl gallate and 3- $t$-butyl-4-hydroxyanisole were used as standards. Five dilutions for each compound and standards were tested. Each dilution was tested in triplicate. After incubation, decrease in absorbance was measured at $517 \mathrm{~nm}$ using microplate reader (Bio-Tek Elx800 TM, Instruments, Inc., USA). Percent radical scavenging activity (\% RSA) of samples was determined in comparison with DMSO treated as control group [22] using the following formula:

$\%$ RSA

$$
=100-\left[\left(\frac{\text { Absorbance of test compound }}{\text { Absorbance of control }}\right) \times 100\right] .
$$

2.4. Antibacterial Activity. The antibacterial activity was evaluated in vitro by minimum inhibitory concentration (MIC) using the serial tube dilution method [23]. For the assay, two Gram-positive bacteria, namely, Staphylococcus aureus and Bacillus subtilis and two Gram-negative bacteria, namely, Escherichia coli and Shigella flexneri were used. Bacterial strains stored in Muller-Hinton broth (Merck) were subcultured for testing in the same medium and were grown at $37^{\circ} \mathrm{C}$ for $24 \mathrm{~h}$ and fresh culture was obtained. Then the cells were suspended, in saline solution, to produce a suspension of about $10^{-5} \mathrm{CFU} \mathrm{mL} \mathrm{mL}^{-1}$ (colony-forming units per $\mathrm{mL}$ ). Serial dilutions of the plants extracts, previously dissolved in N,N-dimethylformamide (DMF), were prepared in test tubes to final concentrations of 2.5, 1.25, 0.625, 0.313, and $0.156 \mu \mathrm{g} / \mathrm{mL} .100 \mu \mathrm{L}$ of a $24 \mathrm{~h}$ old inoculum was added to each tube. The MIC, defined as the lowest concentration of the test compound which inhibits the visible growth after $24 \mathrm{~h}$, was determined visually after incubation at $37^{\circ} \mathrm{C}$. Tests 
using DMF as negative control were carried out in parallel. Ciprofloxacin was used as a control drug. Because the MIC values are not spectacular, no statistical calculations were made.

2.5. Nitric Oxide Generation and Assay of Nitric Oxide Scavenging Method. Nitric oxide (NO) was generated from sodium nitroprusside (SNP) and was measured by the Griess reagent ( $1 \%$ sulphanilamide, $0.1 \%$ naphthylethylenediamine dichloride, and $3 \%$ phosphoric acid). SNP in aqueous solution at physiological $\mathrm{pH}$ spontaneously generates $\mathrm{NO}$ $[24,25]$, which interacts with oxygen to produce nitrite ions that can be estimated by the use of Griess reagent. Scavengers of NO compete with oxygen leading to reduced production of NO [26]. SNP (10 mM) in phosphate buffer saline (PBS) was mixed with different concentrations of extracts $(100-1000 \mu \mathrm{g} / \mathrm{mL})$ of the plants dissolved in ethanol and water and were incubated at $25^{\circ} \mathrm{C}$ for $3 \mathrm{hrs}$. The samples from the above were reacted with Griess reagent. The absorbance of the chromophores formed during the diazotization of nitrite with sulphanilamide, and subsequent coupling with naphthylethylenediamine dichloride (NED) was read at $546 \mathrm{~nm}$ using microplate reader and referred to the absorbance of Ascorbic Acid, used as a positive control treated in the same way with Griess reagent

$$
\begin{aligned}
& \text { Nitric Oxide scavenged }(\%) \\
& =\frac{\left(A_{\text {control }}-A_{\text {test }}\right)}{A_{\text {control }}} \times 100,
\end{aligned}
$$

where $A_{\text {control }}$ is absorbance of control reaction and $A_{\text {test }}$ is absorbance in the presence of the samples of extracts.

2.6. Superoxide Radical Scavenging Assay. This activity was measured by the reduction of NBT according to a previously reported method [27]. The nonenzymatic phenazinemethosulfate-nicotinamide adenine dinucleotide (PMS/NADH) system generates superoxide radicals, which reduce nitro blue tetrazolium (NBT) to a purple formazan. $1 \mathrm{~mL}$ of reaction mixture contained phosphate buffer $(20 \mathrm{mM}, \mathrm{pH} 7.4)$, NADH $(73 \mu \mathrm{M})$, NBT $(50 \mu \mathrm{M})$, PMS $(15 \mu \mathrm{M})$, and various concentrations $(0-20 \mu \mathrm{g} / \mathrm{mL})$ of plants extracts. After incubation for $5 \mathrm{~min}$ at ambient temperature, the absorbance at $562 \mathrm{~nm}$ was measured against an appropriate blank to determine the quantity of formazan generated. All tests were performed in triplicate. Quercetin was used as positive control

$$
\begin{aligned}
& \text { Effect of scavenging (\%) } \\
& \qquad=\left[\frac{1-\text { Absorbance of sample }}{\text { Absorbance of control }}\right] \times 100 .
\end{aligned}
$$

2.7. Total Phenolic Contents. The total phenolic contents of the extracts were determined using the literature method with slight modifications. Calibration curve was prepared by mixing ethanol solution of Gallic acid $(1 \mathrm{~mL} ; 0.025-$ $0.400 \mathrm{mg} / \mathrm{mL}$ ) with $5 \mathrm{~mL}$ Folin-Ciocalteu reagent (diluted tenfold) and sodium carbonate $(4 \mathrm{~mL}, 0.7 \mathrm{M})$. Absorbance values were measured at $765 \mathrm{~nm}$ and the standard curve was drawn. $1 \mathrm{~mL}$ of plant extract $(5 \mathrm{~g} / \mathrm{L})$ was also mixed with the above reagents, and after $30 \mathrm{~min}$ the absorbance was measured to determine the total phenolic contents. All determinations were carried out in triplicate. The total phenolic compounds in the extract in gallic acid equivalents (GAE) were calculated by the following formula:

$$
T=\frac{C \cdot V}{M},
$$

where $T$ is the total phenolic contents, $\mathrm{mg} / \mathrm{g}$ of extract, in GAE; $C$ is the concentration of gallic acid established from the calibration curve, $\mathrm{mg} / \mathrm{mL} ; V$ is the volume of the extract, $\mathrm{mL} ; M$ is the weight of the extract $(\mathrm{g})$.

\section{Results}

3.1. Antioxidant Assay. The percentage radical scavenging activity and thus the degree of discoloration of free radicals by different extracts of Periploca aphylla (PA) and Ricinus communis (RC) were determined against DPPH. The highest percentage of discoloration (61.49\%) of DPPH was observed in the extract of Ricinus communis $n$-butanol extract and lowest $(22.37 \%)$ in chloroform extract of the same plant. Regression equations to derive the $\mathrm{IC}_{50}$ values (concentration of extracts required to scavenge 50\% DPPH free radicals) showed inverse relationship between $\mathrm{IC}_{50}$ value and percentage scavenging potential of a sample. The strongest DPPH radical scavenging activity was exhibited by $n$-butanol extract of RC with $\mathrm{IC}_{50}=140 \pm 0.19 \mu \mathrm{g} / \mathrm{mL}$, while the lowest activity was found in chloroform extract of RC with $\mathrm{IC}_{50}=48560 \pm$ $0.81 \mu \mathrm{g} / \mathrm{mL}$.

In case of Periploca aphylla, crude showed more percentage of discoloration (60.27\%) of DPPH, while the $n$ hexane, chloroform, ethyl acetate, and $n$-butanol fraction showed 57.53, 50.92, 59.05, and 39.11\% inhibitory effects, respectively.

In case of Ricinus communis n-hexane, chloroform, ethyl acetate, and $n$-butanol fraction showed percent discoloration of 56.62, 22.37, 57.99, and 61.49\%, respectively, (Table 1).

3.2. Antibacterial Assay. Two Gram-positive bacteria, namely, Staphylococcus aureus and Bacillus subtilis and two Gram-negative bacteria, namely, Escherichia coli and Shigella flexneri were used for screening the antibacterial activities of Periploca aphylla and Ricinus communis. RC ethyl acetate and chloroform extract were showing more effective MIC values against bacterial strains. These extracts showed same MIC value for E. coli, S. aureus, and S. flexneri and also showed even twofold low MIC value than standard drug for B. subtilis. The least active fraction among all the extracts was $n$-butanol of RC showing 0.625 and $2.50 \mu \mathrm{g} / \mathrm{mL}$, antibacterial activity, against $S$. aureus and $S$. flexneri, respectively (Table 2 ).

3.3. NO Scavenging Assay. Ascorbic acid, an extreme antioxidant, was used as the reference NO radical scavenger in this study. It exhibited potent $\mathrm{NO}$ radical scavenging activity with an $\mathrm{IC}_{50}$ value of $49.98 \pm 0.12 \mu \mathrm{g} / \mathrm{mL}$. 
TABle 1: Antioxidant results of different extracts of Periploca aphylla and Ricinus communis.

\begin{tabular}{lcr}
\hline Plant extract & \% RSA at $500 \mu \mathrm{g} / \mathrm{mL}$ & $\mathrm{IC}{ }_{50}(\mu \mathrm{g} / \mathrm{mL})$ \\
\hline$n$-PG & 92.80 & $40.58 \pm 0.17^{1}$ \\
$t$-BHA & 90.89 & $59.8 \pm 0.43$ \\
PA crude & 60.27 & $137 \pm 0.76$ \\
PA $n$-hexane & 57.53 & $306 \pm 0.47$ \\
PA chloroform & 50.92 & $458 \pm 0.25$ \\
PA ethyl acetate & 59.05 & $150 \pm 0.64$ \\
PA $n$-butanol & 39.11 & $1484 \pm 0.33$ \\
RC $n$-hexane & 56.62 & $193 \pm 0.93$ \\
RC chloroform & 22.37 & $48560 \pm 0.81$ \\
RC ethyl acetate & 57.99 & $190 \pm 0.56$ \\
RC $n$-butanol & 61.49 & $140 \pm 0.19$ \\
\hline
\end{tabular}

${ }^{1}$ Each value in the table was obtained by calculating the average of three experiments \pm standard deviation.

TABLe 2: MIC values ( $\mu \mathrm{g} / \mathrm{mL})$ of different extracts of Periploca aphylla and Ricinus communis.

\begin{tabular}{|c|c|c|c|c|}
\hline Plant extract & E. coli & B. subtilus & S. aureus & S. flexneri \\
\hline Ciprofloxacin & $0.156^{1}$ & 0.625 & 0.156 & 0.313 \\
\hline PA crude & 0.313 & 0.625 & 0.156 & 0.156 \\
\hline PA $n$-hexane & 0.625 & 0.313 & 0.156 & 0.313 \\
\hline PA chloroform & 0.156 & 2.50 & 0.313 & 0.156 \\
\hline PA ethyl acetate & 0.313 & 0.156 & 1.25 & 0.313 \\
\hline PA $n$-butanol & 0.156 & 0.313 & 0.313 & 0.156 \\
\hline RC n-hexane & 0.313 & 1.25 & 0.156 & 0.156 \\
\hline RC chloroform & 0.156 & 0.313 & 0.156 & 0.313 \\
\hline RC ethyl acetate & 0.156 & 0.313 & 0.156 & 0.313 \\
\hline RC $n$-butanol & 0.156 & 0.313 & 0.625 & 2.50 \\
\hline
\end{tabular}

${ }^{1}$ Each value in the table was obtained by observing the average of three experiments.

The $\mathrm{IC}_{50}$ values of crude, $n$-hexane, chloroform, ethyl acetate, and $n$-butanol fractions of Periploca aphylla were $143.18 \pm 0.49,124.46 \pm 0.32,103.29 \pm 0.52,115.07 \pm 0.28$, and $113.82 \pm 0.43 \mu \mathrm{g} / \mathrm{mL}$, respectively, showing that PA chloroform extract has lower $\mathrm{IC}_{50}$ value as compared to other extracts of this plant. The $\mathrm{IC}_{50}$ values of $n$-hexane, chloroform, ethyl acetate, and $n$-butanol fractions of Ricinus communis of were $173.45 \pm 0.84,231.36 \pm 0.91,109.77 \pm 0.66$, and $92.29 \pm 0.72 \mu \mathrm{g} / \mathrm{mL}$, respectively. In the extracts of RC, $n$ butanol extract showed lower $\mathrm{IC}_{50}$ value compared to other extracts (Table 3 ).

3.4. Superoxide Scavenging Assay. The ability to reduce NBT can be measured by superoxide radicals generated from dissolved oxygen by PMS-NADH coupling. The decrease in absorbance at $562 \mathrm{~nm}$ with the plant extracts and the reference compound quercetin indicates their abilities to quench superoxide radicals in the reaction mixture. The \% RSA value of quercetin, taken as standard, on superoxide scavenging activity was $42.06 \pm 0.35 \mu \mathrm{g} / \mathrm{mL}$ (Table 4 ). The $\%$ RSA values of Periploca aphylla crude, $n$-hexane, chloroform, ethyl acetate, and $n$-butanol extracts on superoxide radical were $58.35 \pm 0.76,53.97 \pm 0.52,69.11 \pm 0.69,68.96 \pm 0.84$, and $71.05 \pm 0.44 \mu \mathrm{g} / \mathrm{mL}$, respectively. The \% RSA values of Ricinus communis $n$-hexane, chloroform, ethyl acetate, and $n$-butanol extracts on superoxide radical were $37.19 \pm$ $0.39,56.99 \pm 0.48,55.03 \pm 0.97$, and $66.79 \pm 0.65 \mu \mathrm{g} / \mathrm{mL}$, respectively. The \% RSA values of $n$-hexane extract of both plants were less than other extracts of the same plants.

3.5. Total Phenolic Contents. Table 5 shows the contents of total phenols that were measured by Folin-Ciocalteu reagent in terms of gallic acid equivalent (standard curve equation: $\left.y=0.004 x+0.086, R^{2}=0.903\right)$. The total phenols varied from $42 \pm 8$ to $156 \pm 5 \mathrm{mgg}^{-1}$ in the extracts of $\mathrm{PA}$, and from $52 \pm 7$ to $89 \pm 6 \mathrm{mg} / \mathrm{g}$ in RC extracts. PA crude methanolic extract with the total phenol contents of $156 \pm$ $5 \mathrm{mg} / \mathrm{g}$ had the highest amount among all the other fractions. It may be due to the reason that all phenolic contents were concentrated in crude and then in fractionation process these go to all subfractions. Thus fractions contain less phenolic contents as compared to crude.

\section{Discussion}

Table 1 shows the percentage of DPPH radical scavenged by standards, that is, $n$-propyl gallate and 3-t-butyl-4hydroxyanisole and different extracts of 2 plants at various concentrations $(\mu \mathrm{g} / \mathrm{mL})$. Scavenging activities of these plants are comparable with standards. It is evident from the 
TABLe 3: NO scavenging activity of different extracts of Periploca aphylla and Ricinus communis.

\begin{tabular}{lcr}
\hline Plant extract & \% RSA at $500(\mu \mathrm{g} / \mathrm{mL})$ & $\mathrm{IC}(\mu \mathrm{g} / \mathrm{mL})$ \\
\hline Ascorbic acid & 80.54 & $49.98 \pm 0.12^{1}$ \\
PA crude & 58.89 & $143.18 \pm 0.49$ \\
PA $n$-hexane & 60.58 & $124.46 \pm 0.32$ \\
PA chloroform & 64.04 & $103.29 \pm 0.52$ \\
PA ethyl acetate & 61.53 & $115.07 \pm 0.28$ \\
PA $n$-butanol & 61.29 & $113.82 \pm 0.43$ \\
RC $n$-hexane & 55.10 & $173.45 \pm 0.84$ \\
RC chloroform & 53.20 & $231.36 \pm 0.91$ \\
RC ethyl acetate & 63.08 & $109.77 \pm 0.66$ \\
RC $n$-butanol & 66.57 & $92.29 \pm 0.72$ \\
\hline
\end{tabular}

${ }^{1}$ Each value in the table was obtained by calculating the average of three experiments \pm standard deviation.

TABLE 4: Superoxide radical scavenging assay of different extracts of Periploca aphylla and Ricinus communis.

\begin{tabular}{lc}
\hline Plant extract & \% RSA in $(\mu \mathrm{g} / \mathrm{mL})$ \\
\hline Quercetin & $42.06 \pm 0.35^{1}$ \\
PA crude & $58.35 \pm 0.76$ \\
PA $n$-hexane & $53.97 \pm 0.52$ \\
PA chloroform & $69.11 \pm 0.69$ \\
PA ethyl acetate & $68.96 \pm 0.84$ \\
PA $n$-butanol & $71.05 \pm 0.44$ \\
RC $n$-hexane & $37.19 \pm 0.39$ \\
RC chloroform & $56.99 \pm 0.48$ \\
RC ethyl acetate & $55.03 \pm 0.97$ \\
RC $n$-butanol & $66.79 \pm 0.65$ \\
\hline
\end{tabular}

${ }^{1}$ Each value in the table was obtained by calculating the average of three experiments \pm standard deviation.

TABle 5: Phenolic contents of different extracts of Periploca aphylla and Ricinus communis.

\begin{tabular}{lc}
\hline Plant extract & Phenol (mg/g) \\
\hline PA crude & $156 \pm 5^{1}$ \\
PA $n$-hexane & $79 \pm 3$ \\
PA chloroform & $47 \pm 6$ \\
PA ethyl acetate & $58 \pm 2$ \\
PA $n$-butanol & $42 \pm 8$ \\
RC $n$-hexane & $89 \pm 6$ \\
RC chloroform & $60 \pm 3$ \\
RC ethyl acetate & $73 \pm 2$ \\
RC $n$-butanol & $52 \pm 7$ \\
\hline
\end{tabular}

${ }^{1}$ Each value in the table was obtained by calculating the average of three experiments \pm standard deviation.

data that Periploca aphylla and Ricinus communis possess hydrogen donating capabilities and free radical scavenging ability and can act as antioxidants.

All the extracts of both plants were tested against bacterial strains and each extract showed potent antibacterial activity. Two extracts of RC showed potent antibacterial activity. $n$-hexane of RC and crude and chloroform extracts of PA showed least tested concentration against two bacterial strains; it means these extracts have significant antibacterial activity.

All the tested extracts of both plants exhibited strong NO radical scavenging activity with low $\mathrm{IC}_{50}$ values. Hence these plants can act as NO radical scavengers. Regarding the \%RSA values, the extracts showing high $\mathrm{IC}_{50}$ values have shown less scavenging activity, whereas extracts having low $\mathrm{IC}_{50}$ value means that they are more potent scavengers of NO radical.

The results suggest that the $n$-hexane of Ricinus communis was a less potent scavenger of superoxide radical than the standard quercetin, whereas all the fractions of Periploca aphylla and Ricinus communis showed more potent scavenging effects as compared to quercetin at $20 \mu \mathrm{g} / \mathrm{mL}$.

The results showed significant total phenolic contents in the extracts of Periploca aphylla and Ricinus communis. The extract of Periploca aphylla, which contains highest quantity of phenolic compounds, exhibited the greatest antioxidant activity. The high scavenging property of Periploca aphylla may be due to hydroxyl groups existing in the phenolic compounds that can provide the necessary component as a radical scavenger. All the extracts of both plants exhibited different extent of antioxidant activity. Crude extract of Periploca aphylla and $n$-butanol extract of Ricinus communis showed a higher potency in scavenging of DPPH free radical. This may be related to the high amount of phenolic compounds in these plant extracts.

\section{Conclusions}

In the present study, in vitro free radical scavenging activities indicated that both the plants have significant radicals scavenging abilities on DPPH, NO, and superoxide radicals. The scavenging effects were powerful, close to the positive controls used in respective assays. Therefore, Periploca aphylla and Ricinus communis should be explored as novel potential antioxidants. The extracts of the aerial parts of the plants may be used in therapeutically relevance. On the other hand, some extracts showed significant, moderate, and even weak antibacterial activities compared to the reference. Therefore, further investigations of their in vivo antioxidant activities must be elucidated and carried out. Further studies 
are needed to better characterize the important active constituents responsible for the free radical scavenging activity.

\section{Conflict of Interests}

The authors report no conflict of interests.

\section{References}

[1] R. Marchioli, C. Schweiger, G. Levantesi, L. Tavazzi, and F. Valagussa, "Antioxidant vitamins and prevention of cardiovascular disease: epidemiological and clinical trial data," Lipids, vol. 36, pp. S53-S63, 2001.

[2] S. A. Stanner, J. Hughes, C. N. M. Kelly, and J. Buttriss, "A review of the epidemiological evidence for the 'antioxidant hypothesis', Public Health Nutrition, vol. 7, no. 3, pp. 407-422, 2004.

[3] Š. Ozgová, J. Heřmánek, and I. Gut, "Different antioxidant effects of polyphenols on lipid peroxidation and hydroxyl radicals in the NADPH-, Fe-ascorbate- and Fe-microsomal systems," Biochemical Pharmacology, vol. 66, no. 7, pp. 11271137, 2003.

[4] D. S. Bredt and S. H. Snyder, "Nitric oxide: a physiological messenger molecule," Annual Review of Biochemistry, vol. 63, pp. 175-195, 1994.

[5] K. Shibuki and D. Okada, "Endogenous nitric oxide release required for long-term synaptic depression in the cerebellum," Nature, vol. 349, no. 6307, pp. 326-328, 1991.

[6] S. Moncada, R. M. J. Palmer, and E. A. Higgs, "Nitric oxide: physiology, pathophysiology, and pharmacology," Pharmacological Reviews, vol. 43, no. 2, pp. 109-142, 1991.

[7] T. M. Dawson, V. L. Dawson, and S. H. Snyder, "A novel neuronal messenger molecule in brain: the free radical, nitric oxide," Annals of Neurology, vol. 32, no. 3, pp. 297-311, 1992.

[8] K. Umehara, N. Sumii, H. Satoh, T. Miyase, M. Kuroyanagi, and A. Ueno, "Studies on differentiation inducers. V. Steroid glycosides from periplocae radicis cortex," Chemical and Pharmaceutical Bulletin, vol. 43, no. 9, pp. 1565-1568, 1995.

[9] H. Itokawa, J. Xu, and K. Takeya, "Studies on chemical constituents of antitumor fraction from Periploca sepium. V. Structures of new pregnane glycosides, periplocosides J, K, F and O," Chemical and Pharmaceutical Bulletin, vol. 36, no. 11, pp. 4441-4446, 1988.

[10] G. Mustafa, E. Anis, S. Ahmed et al., "Lupene-type triterpenes from Periploca aphylla," Journal of Natural Products, vol. 63, no. 6, pp. 881-883, 2000.

[11] R. Ilavarasan, M. Mallika, and S. Venkataraman, "Antiinflammatory and free radical scavenging activity of Ricinus communis root extract," Journal of Ethnopharmacology, vol. 103, no. 3, pp. 478-480, 2006.

[12] P. Shokeen, P. Anand, Y. K. Murali, and V. Tandon, "Antidiabetic activity of $50 \%$ ethanolic extract of Ricinus communis and its purified fractions," Food and Chemical Toxicology, vol. 46, no. 11, pp. 3458-3466, 2008.

[13] H. X. Wang and T. B. Ng, "Examination of lectins, polysaccharopeptide, polysaccharide, alkaloid, coumarin and trypsin inhibitors for inhibitory activity against human immunodeficiency virus reverse transcriptase and glycohydrolases," Planta Medica, vol. 67, no. 7, pp. 669-672, 2001.

[14] C. O. Isichei, S. C. Das, O. O. Ogunkeye et al., "Preliminary clinical investigation of the contraceptive efficacy and chemical pathological effects of RICOM-1013-J of Ricinus communis var minor on women volunteers," Phytotherapy Research, vol. 14 , no. 1, pp. 40-42, 2000.

[15] E. Makonnen, L. Zerihun, G. Assefa, and A. A. H. Rostom, "Antifertility activity of Ricinus communis seed in female guinea pigs," East African Medical Journal, vol. 76, no. 6, pp. 335-337, 1999.

[16] F. K. Okwuasaba, U. A. Osunkwo, M. M. Ekwenchi et al., "Anticonceptive and estrogenic effects of a seed extract of Ricinus communis var. minor," Journal of Ethnopharmacology, vol. 34, no. 2-3, pp. 141-145, 1991.

[17] Y. Raji, A. K. Oloyo, and A. O. Morakinyo, "Effect of methanol extract of Ricinus communis seed on reproduction of male rats," Asian Journal of Andrology, vol. 8, no. 1, pp. 115-121, 2006.

[18] K. Sandhyakumary, R. G. Bobby, and M. Indira, "Antifertility effects of Ricinus communis (Linn) on rats," Phytotherapy Research, vol. 17, no. 5, pp. 508-511, 2003.

[19] A. C. Ferraz, M. E. M. Angelucci, M. L. Da Costa, I. R. Batista, B. H. De Oliveira, and C. Da Cunha, "Pharmacological evaluation of ricinine, a central Nervous system stimulant isolated from Ricinus communis," Pharmacology Biochemistry and Behavior, vol. 63, no. 3, pp. 367-375, 1999.

[20] S. M. Upasani, H. M. Kotkar, P. S. Mendki, and V. L. Maheshwari, "Partial characterization and insecticidal properties of Ricinus communis L. foliage flavonoids," Pest Management Science, vol. 59, no. 12, pp. 1349-1354, 2003.

[21] M. I. Choudhary, A. Begum, A. Abbaskhan, S. G. Musharraf, A. Ejaz, and Atta-ur-Rahman, "Two new antioxidant phenylpropanoids from Lindelofia stylosa," Chemistry and Biodiversity, vol. 5, no. 12, pp. 2676-2683, 2008.

[22] S. K. Lee, Z. H. Mbwambo, H. Chung et al., "Evaluation of the antioxidant potential of natural products," Combinatorial Chemistry and High Throughput Screening, vol. 1, no. 1, pp. 35-46, 1998.

[23] I. C. Zampini, S. Cuello, M. R. Alberto et al., "Antimicrobial activity of selected plant species from "the Argentine Puna" against sensitive and multi-resistant bacteria," Journal of Ethnopharmacology, vol. 124, no. 3, pp. 499-505, 2009.

[24] L. C. Green, D. A. Wagner, and J. Glogowski, "Analysis of nitrate, nitrite, and [15N]nitrate in biological fluids," Analytical Biochemistry, vol. 126, no. 1, pp. 131-138, 1982.

[25] L. Marcocci, J. J. Maguire, M. T. Droy-Lefaix, and L. Packer, "The nitric oxide-scavenging properties of Ginkgo biloba extract EGb 761," Biochemical and Biophysical Research Communications, vol. 201, no. 2, pp. 748-755, 1994.

[26] L. Marcocci, L. Packer, M. T. Droy-Lefaix, A. Sekaki, and M. Gardes-Albert, "Antioxidant action of Ginkgo biloba extract EGb 761," Methods in Enzymology, vol. 234, pp. 462-475, 1994.

[27] M. Fontana, L. Mosca, and M. A. Rosei, "Interaction of enkephalins with oxyradicals," Biochemical Pharmacology, vol. 61, no. 10, pp. 1253-1257, 2001. 

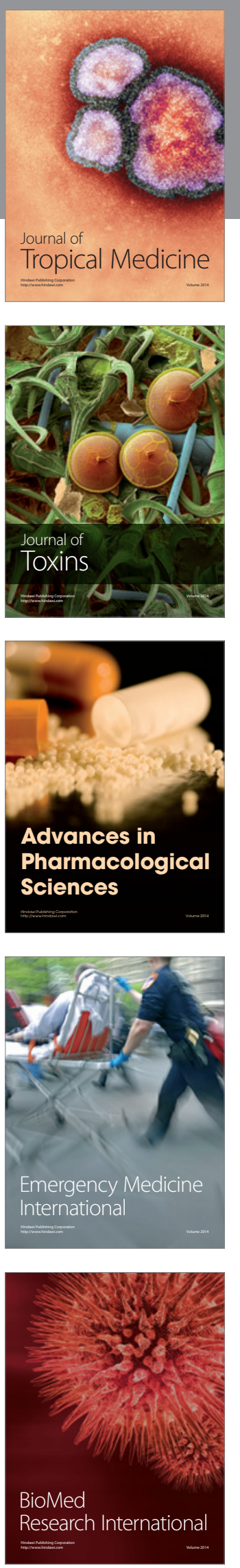
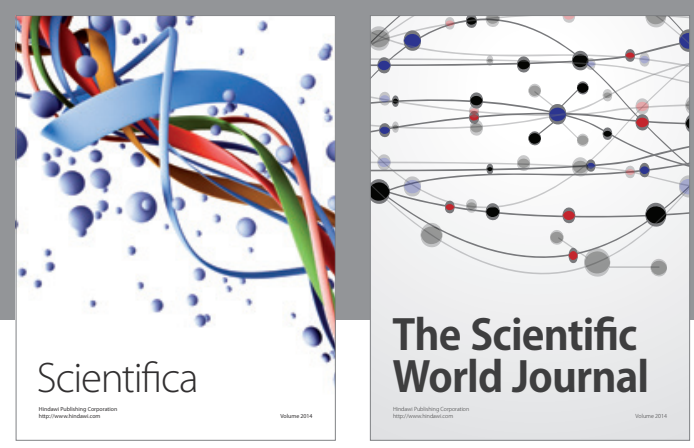

The Scientific World Journal
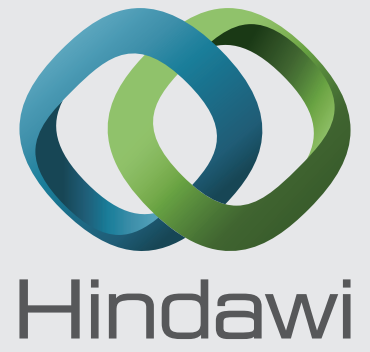

Submit your manuscripts at

http://www.hindawi.com
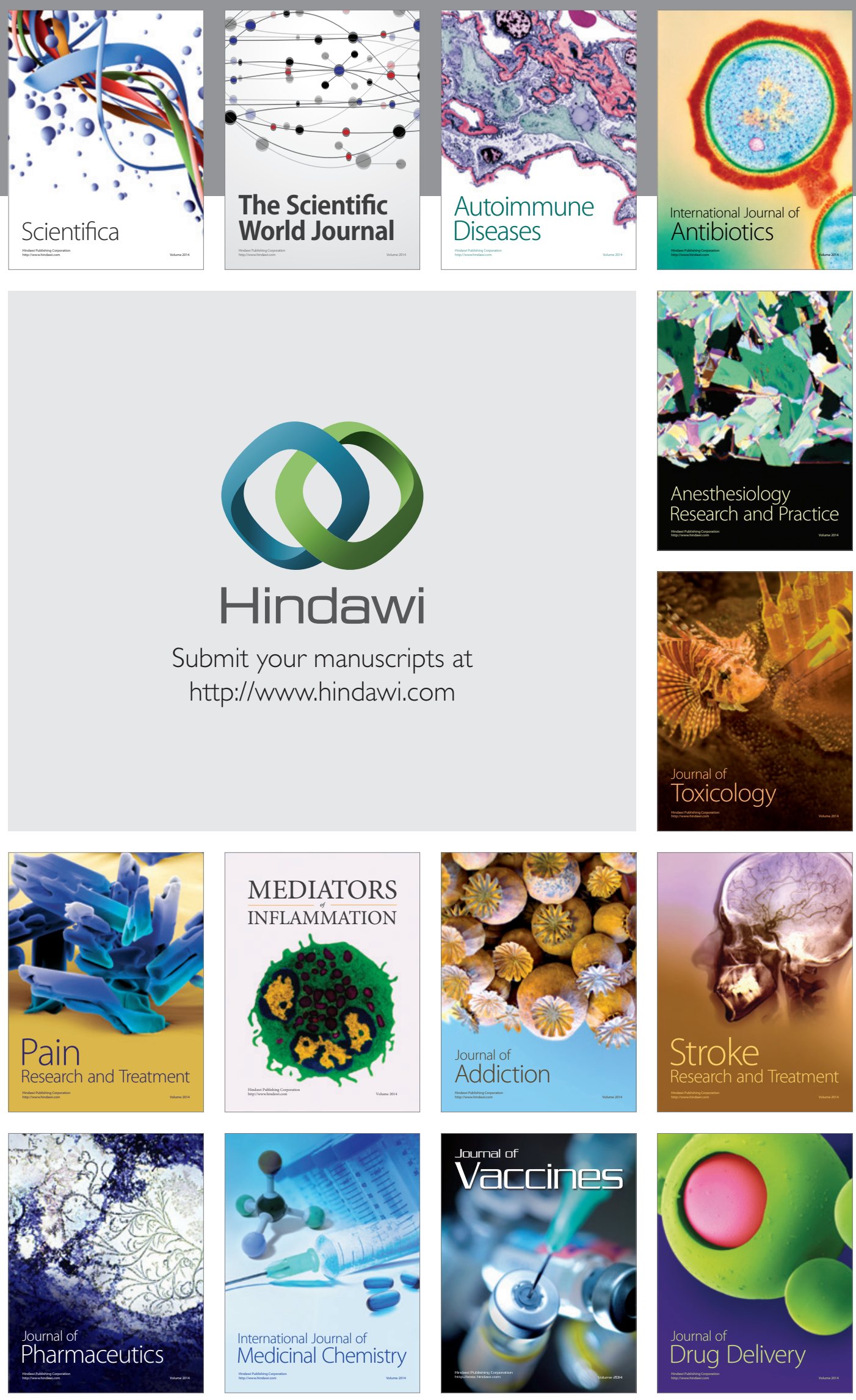